\title{
Cold hardiness as a factor for assessing the potential distribution of the Japanese pine sawyer Monochamus alternatus (Coleoptera: Cerambycidae) in China
}

\author{
Rui-Yan MA ${ }^{\mathrm{a}, \mathrm{b}}$, Shu-Guang HAO ${ }^{\mathrm{a}}$, Wei-Na KONG ${ }^{\mathrm{b}}$, Jiang-Hua SUN ${ }^{\mathrm{a}}$, Le KANG ${ }^{\mathrm{a} *}$ \\ a State Key Laboratory of Integrated Management of Pest Insects and Rodents, Institute of Zoology, Chinese Academy of Sciences, \\ Beijing 100080, China \\ ${ }^{\mathrm{b}}$ Department of Entomology, Shanxi Agricultural University, Taigu 030801, China
}

(Received 31 May 2005; accepted 3 November 2005)

\begin{abstract}
To assess cold tolerance as a factor for potential distribution of Monochamus alternatus, parameters of cold hardiness and acclimation responses of the beetle were examined. Supercooling points (SCPs) of eggs, larvae, pupae, and adults were significantly different, the eggs having the lowest value $\left(-19.8^{\circ} \mathrm{C}\right)$ and the adults the highest $\left(-6.6^{\circ} \mathrm{C}\right)$. No significant differences were observed between the SCPs of pupae and overwintering 5 th instar larvae, but mean SCPs significantly declined with the development of larval instars. Mortality of overwintering larvae increased as temperature declined and exposure to low temperatures was prolonged. No individual survived at $-25{ }^{\circ} \mathrm{C}$. Lethal times of $\mathrm{Lt}_{50}$ and $\mathrm{Lt}_{95} \mathrm{were} 35.8 \mathrm{~d}$ and $65.4 \mathrm{~d}$ at $-10{ }^{\circ} \mathrm{C}$, respectively. Acclimation significantly improved cold tolerance of autumn 4-5th instar larvae, but not of overwintering larvae. Based on these results, the $-10{ }^{\circ} \mathrm{C}$ January mean air temperature isotherm is suggested as the northern limit of the beetle potential distribution in China.
\end{abstract}

Monochamus alternatus / cold tolerance / acclimation / distribution limit / isotherm

Résumé - La résistance au froid comme facteur pour évaluer la distribution potentielle du scieur de pin japonais Monochamus alternatus (Coleoptera : Cerambycidae) en Chine. Afin d'estimer la résistance au froid et les capacités de dispersion de Monochamus alternatus, nous avons étudié les réponses de ce coléoptère à la rigueur hivernale, avec ou sans acclimatation. La valeur moyenne du point de super-congélation (SCP) est sensiblement différente entre les œufs, les larves, les chrysalides, et les adultes, les œufs présentant la valeur la plus basse $\left(-19.8^{\circ} \mathrm{C}\right)$ et les adultes la plus élevée $\left(-6.6^{\circ} \mathrm{C}\right)$. Bien que cette valeur moyenne de SCP ait progressivement diminué au fur et à mesure du développement larvaire, aucune différence significative n'a été observée entre les larves hivernantes de $5^{\mathrm{e}}$ stade et les chrysalides. La mortalité des larves hivernantes augmente avec la diminution de la température et avec la durée d'exposition aux basses températures. Aucun œuf, larve, chrysalide ou adulte ont survécu à une exposition à $-25^{\circ} \mathrm{C}$. Pour une température de $-10{ }^{\circ} \mathrm{C}$, la durée létale d'exposition a été établie à $35.8 \mathrm{~d}\left(\mathrm{Lt}_{50}\right)$ et $65.4 \mathrm{~d}\left(\mathrm{Lt}_{95}\right)$. L'acclimatation préalable a augmenté de manière significative la tolérance au froid des larves de $4^{\mathrm{e}}$ et $5^{\mathrm{e}}$ stades présentes en automne, mais pas celle des larves hivernantes. L'isotherme $-10{ }^{\circ} \mathrm{C}$ pour la température moyenne de l'air en janvier a été proposé comme limite septentrionale de la distribution de coléoptère en Chine.

Monochamus alternatus / tolérance au froid acclimatation / limite de distribution / isotherme

\section{INTRODUCTION}

The pine wood nematode (PWN) Bursaphelenchus xylophilus (Steiner and Buhrer) Nickle (Nematoda: Aphelenchoididae), originating from North America, causes destructive pine wilt disease $[11,13]$. Factors influencing occurrence and distribution of the disease include the climate and topography, nematode pathogenicity, vector biology and distribution of susceptible tree species [19]. As a main vector of the disease and a serious pine forest pest itself, the Japanese pine sawyer, Monochamus alternatus Hope (Coleoptera: Cerambycidae) has caused economic losses of approximately 3 million US dollars per year in China since B. xylophilus was first discovered in Nanjing City in 1982 [5]. The beetle usually has one generation per year in central China, but occasionally develops two generations in Guangdong province of tropical southern

\footnotetext{
*Corresponding author: 1kang@ioz.ac.cn
}

China [26]. The beetle overwinters as 4th or 5th instar larvae in the xylem of the host stems from December to February in Anhui province, a main distribution region of the beetle. Adult emergence may last for two months, peaking in July. The distribution range of the beetle in China appears to be more restricted than that of its host trees, but larger than the distribution of the PWN [16]. Therefore, determination of the northern limit for distribution and forecast of potential dispersal regions of the beetle has important significance in the management of the pine wood nematode, a serious invasive pest in China.

Generally, high-latitude distribution limits of a forest insect species can be constrained by the occurrence of host plants, mortality from low winter temperatures [22], and summer temperatures that limit development rate [1]. In Japan, host trees of M. alternatus have been recorded from 22 species of gymnosperm plants [11]. In China, host plants of the beetle are principally in 5 genera (Pinus, Abies, Picea, Larix and 
Cedrus), including $P$. massoniana, $P$. thunbergii, $P$. densiflora, P. bungeana, $P$. pinaster, $P$. tabulaeformis, $P$. taeda, $P$. elliottii, $P$. tanwanensis, $P$. armandii, $P$. yunnanensis, $P$. luchuensis, and Cedrus daeodar, $P$. massoniana being recorded as the most susceptible host tree $[21,29]$. Therefore, host tree distribution is not the limiting factor for beetle dispersal in China. The northern limit of the beetle distribution area was reported to be the $40^{\circ}$ northern latitude in Japan, except for areas of Hokkaido and northern Honshu, where the limiting factor was the lack of sufficiently high temperatures in the summer [11]. In most parts of China, apart from the western high-plateaux, the sum of effective temperatures is high enough for the beetle development during the summer. Several researchers have reported that winter cold is one of the most important factors that limit the distribution of insects in the high-latitude zones $[4,12,20,23]$. We suggest that low temperatures in winter also play an important role in limiting the distribution and dispersal range of the beetle in China. Due to the wide range of topographic conditions, the $40^{\circ}$ northern latitude is not appropriate as the northern limit of the beetle's distribution in China.

Cold tolerance in temperate regions is a critical feature in determining insect population survival and overwintering, potential establishment and geographical distribution and risk of outbreak status $[2,3,12,15,17]$. Consequently, cold tolerance and overwintering biology as an assessment of population establishment in given geographical areas have been applied to Thrips palmmi in the United Kingdom [15] and to 30 species of drosophilid flies in Japan [10]. Besides, the northern distribution limits of Dendroctonus frontalis in the United States [23], Strophingia ericae and Strophingia cinereae in the United Kingdom [7] and Liriomyza sativae in China [4] were estimated successfully through studies of their cold tolerances including supercooling points (SCPs), survival under low temperatures and acclimation efficiency [9].

Within the family of long-horned beetles, only the cold hardiness of eggs and neonatal larvae of the yellow-spotted longicorn beetle Psacothea hilaris have been studied in Japan [20]. Although several studies have been conducted on the biology of the Japanese pine sawyer and its vectoring nematode $B$. $x y$ lophilus $[11,13,14]$, research on its cold tolerance is still lacking. The objectives of the present study were to determine the nature of cold tolerance of $M$. alternatus as a basis for predicting its potential distribution and dispersal, based on its cold hardiness, and to further evaluate the risks of transmission of the pine wilt disease in China.

\section{MATERIALS AND METHODS}

\subsection{Collection of insects}

Eggs, larvae, pupae and adults of M. alternatus were collected from host trees of Pinus massoniana, in Xuancheng County (E $118^{\circ}$ $28^{\prime}, \mathrm{N} 30^{\circ} 35^{\prime}$, Altitude 75-125 m), Anhui province, China, between April 2003 and June 2004. Pupae, adults and eggs were collected during their peak periods (from June to August), autumn 4-5th instar larvae were collected in November and overwintering larvae were collected in January. Eggs were removed from oviposition scars between the phloem and the periderm in the tree stems, and larvae and pupae were obtained by splitting the pine tree stems. Larvae, pupae and adults were placed singly in a $7 \mathrm{~mL}$ plastic tube with a $2-3 \mathrm{~mm}$ hole in the lid.

\subsection{Measurement of supercooling points (SCPs)}

The lowest temperature at which the supercooling of the body fluids ceases is called the Supercooling point. It corresponds to the onset of a sharp rebound on the thermal curve due to the release of the latent heat of ice crystallization. The SCPs of the individuals at different developmental stages were measured using the method described by Jing and Kang [8]. Numbers of assayed individuals of eggs, larvae, pupae and adults were 20,100, 20 and 30, respectively. To measure the SCP, each egg was attached to the tip of a thermocouple, which was placed on the 4th tergum of larvae and pupae, and under the wing base tergum in adults. The freezing chambers were cooled gradually at a rate of $1{ }^{\circ} \mathrm{C} \mathrm{min}^{-1}$ during measurements.

\subsection{Mortality at low temperatures}

To compare the effects of low temperatures, mortality of the eggs, overwintering 4-5th instar larvae, pupae and adults at low temperatures were examined. Eggs were incubated on moistened filter paper in $60 \mathrm{~mm}$ diameter Petri dishes. Each larva, pupa or adult was placed singly in a $7 \mathrm{~mL}$ plastic tube to avoid cannibalism. All eggs, pupa and adult individuals were exposed to low temperatures from -25 to $5{ }^{\circ} \mathrm{C}$ with $5{ }^{\circ} \mathrm{C}$ increments for $1 / 16 \mathrm{~d}$, but overwintering 4-5th instar larvae were conducted at 7 low temperatures (from -25 to $5{ }^{\circ} \mathrm{C}$ with $5{ }^{\circ} \mathrm{C}$ increments), and exposed to 6 different periods $(1 / 16 \mathrm{~d}, 1 / 4 \mathrm{~d}$, $1 \mathrm{~d}, 4 \mathrm{~d}, 16 \mathrm{~d}$, and $32 \mathrm{~d}$ ) at each temperature, respectively. Twenty individuals for each treatment were used in each of 4 replicates for all treatments. Control groups with 4 replicates, were maintained under standard conditions $\left(T=25^{\circ} \mathrm{C}, \mathrm{D}: \mathrm{L}=24: 0, \mathrm{RH}=75 \%\right)$.

After cold exposure, all individuals were returned to the standard conditions like the control group to recover for $1 \mathrm{~d}$. Survival of the four developmental stages was measured. Dead condition of larvae and adults were determined by the absence of mandible or body movement when stimulated with a needle. Surviving eggs and pupae were determined by eggs hatching or adult eclosion after 1 or 2 weeks.

\subsection{Acclimation efficiency}

To examine the effect of low temperature acclimation on cold hardiness, both autumn and overwintering 4-5th instar larvae were acclimated at 5 and $0{ }^{\circ} \mathrm{C}$ for periods of $1 / 4 \mathrm{~d}, 1 \mathrm{~d}$ and $4 \mathrm{~d}$. After acclimation, both kinds of larvae were divided into two groups, one was used to measure the SCP, and the other was used to test the mortality when exposed to low temperature. The autumn larvae were exposed to $-10{ }^{\circ} \mathrm{C}$ for $1 / 4 \mathrm{~d}$ and the overwintering larvae were exposed to $-15{ }^{\circ} \mathrm{C}$ for $1 / 4 \mathrm{~d}$. As controls, non-acclimated autumn and overwintering 4-5th instar larvae were directly exposed to $-10{ }^{\circ} \mathrm{C}$ for $1 / 4 \mathrm{~d}$ or $-15{ }^{\circ} \mathrm{C}$ for $1 / 4 \mathrm{~d}$ respectively. Twenty larvae were used in each of the four replicates of every treatment. After cold exposure, all individuals were returned to the standard conditions like the control group to recover for $1 \mathrm{~d}$. Dead condition of larvae was determined as mentioned above. 


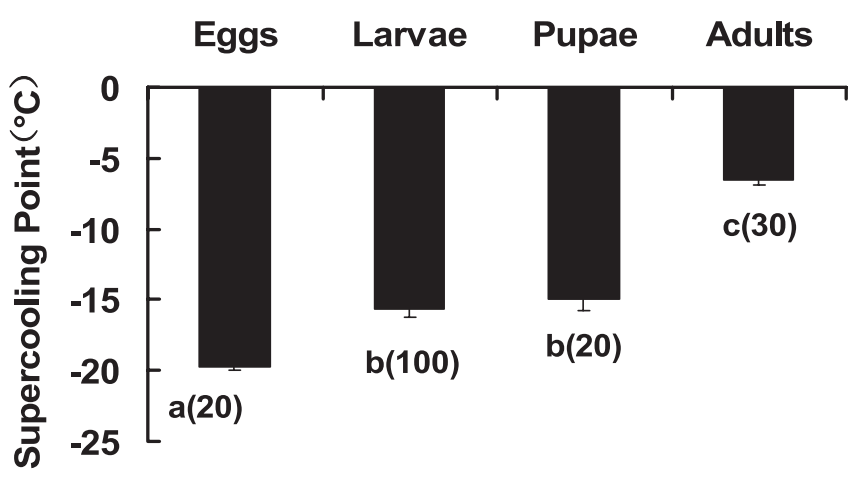

Figure 1. Mean supercooling points (SCPs) of Monochamus alternatus at different developmental stages. The columns followed by different letters are significantly different (Duncan's multiple range test at $\alpha=0.05$ ). Figures in parentheses indicate number of individuals tested. The bar line is S.E.

\subsection{Statistical analysis}

One-way ANOVAs and Duncan's multiple range tests were used to compare the differences in SCPs and mortalities among the developmental stages. Mortality percentage was transformed using an arcsine square-root method to correct it before data analysis. Lethal times $\left(\mathrm{Lt}_{50}\right.$ and $\mathrm{Lt}_{95}$ : durations causing 50\% and 95\% mortality, respectively) and lethal temperature $\left(\mathrm{LT}_{50}\right.$ : temperature causing $50 \%$ mortality) at specific temperatures or specific time, were determined with a 95\% fiducial limit by Probit analysis (SPSS 10.0). Differences between lethal dose estimates were considered statistically significant if fiducial limits did not overlap [15].

\section{RESULTS}

\subsection{Supercooling points}

The mean SCPs of M. alternatus significantly differed between the four developmental stages (egg, 5th instar overwintering larva, pupa and adult $)(\mathrm{F}=45.124$, d.f. $=3,166$, $* * * P<0.001)$ (Fig. 1). The SCP of eggs $\left(-19.8 \pm 0.2{ }^{\circ} \mathrm{C}\right)$ was the lowest, whereas that of adults $\left(-6.6 \pm 0.3{ }^{\circ} \mathrm{C}\right)$ was the highest. Significant differences were observed between eggs and overwintering 5 th instar larvae, pupae and adults, between overwintering 4-5th instar larvae and adults, but not between 5th instar larvae $\left(15.7 \pm 0.5^{\circ} \mathrm{C}\right)$ and pupae $\left(15.0 \pm 0.8^{\circ} \mathrm{C}\right)$ (Fig. 1).

The mean SCPs of overwintering larvae differed significantly between the 5 instars $(F=3.992$, d.f. $=4,180$, $* * P<0.01$ ), declining gradually from the 1 st to the 5th instar (Fig. 2). The mean SCPs of the 1st and 2nd instar larvae were significantly higher than that of the 5th instar larvae, but there was no significant difference between the SCPs of the 4th and 5th instar larvae. The mean SCP of the 5th instar larvae $\left(-15.7 \pm 0.5^{\circ} \mathrm{C}\right)$ was the lowest, whereas $1 \mathrm{st}$ instar larvae $\left(-12.1 \pm 1.0^{\circ} \mathrm{C}\right)$ had the highest values (Fig. 2).

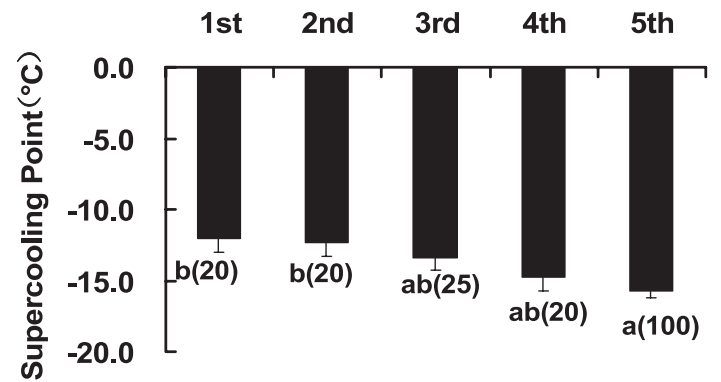

Figure 2. Mean supercooling point (SCP) of Monochamus alternatus for different instars of overwintering larvae. The columns followed by different letters are significantly different (Duncan's multiple range test at $\alpha=0.05$ ). Figures in parentheses indicate number of individuals tested. The bar line is S.E.

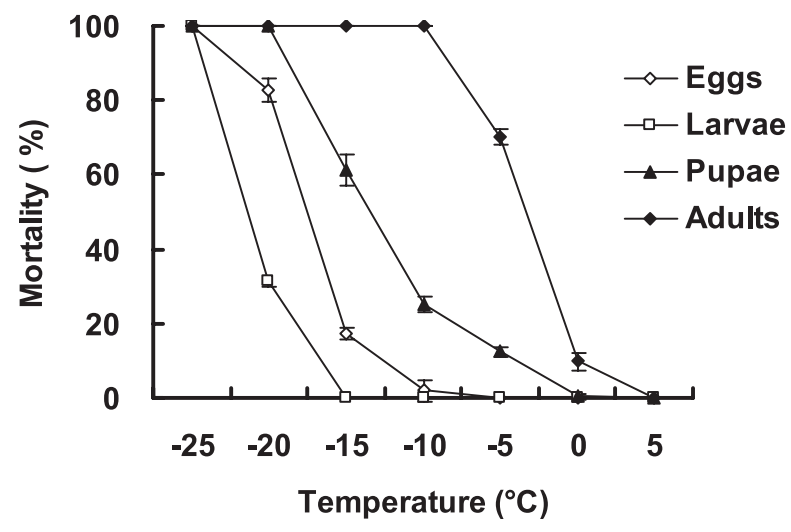

Figure 3. Mortality (mean \pm S.E.) of different developmental stages of Monochamus alternatus after exposure to low temperatures for $1 / 16 \mathrm{~d}$. The bar line is S.E.

\subsection{Mortality at low temperatures}

Mortality of each developmental stage of the larvae increased as the temperature decreased (Fig. 3). There were significant differences between developmental stages tested when exposed to low temperatures, and no individuals survived at $-25^{\circ} \mathrm{C}$ and none died at $5{ }^{\circ} \mathrm{C}$ (Fig. 3). When adults were exposed to $-10{ }^{\circ} \mathrm{C}$ and below, mortality reached $100 \%$. Where only overwintering larvae occurred at $-20{ }^{\circ} \mathrm{C}$, mortality reached $31.2 \%$. When exposed to low temperatures for $1 / 16 \mathrm{~d}$, $\mathrm{LT}_{50}$ of eggs, larvae, pupae and adults were $-17.3,-21.3$, 12.4 and $-3.5{ }^{\circ} \mathrm{C}$, respectively. Cold tolerance of the overwintering larvae was the highest of all developmental stages (Fig. 3).

Survival of overwintering 4-5th instar larvae at low temperatures declined when temperature decreased (Tab. I). No individuals survived at $-25^{\circ} \mathrm{C}$, but $\mathrm{Lt}_{95}$ increased rapidly to $65.4 \mathrm{~d}$ at $-10{ }^{\circ} \mathrm{C}$. There were no significant differences either in the $\mathrm{Lt}_{50}$ or the $\mathrm{Lt}_{95}$ of the overwintering larvae in the range of 5 to $25{ }^{\circ} \mathrm{C}$ (control) due to overlapping 95\% fiducial limits. However, when temperature decreased to $-15^{\circ} \mathrm{C}$ nearing the mean SCP, mortality increased significantly with longer duration of exposure to low temperature (Tab. I). 
Table I. $\mathrm{Lt}_{50}, \mathrm{Lt}_{95}$ and $95 \%$ fiducial limits of Monochamus alternatus overwintering 4-5th instar larvae exposed to low temperatures for different times (Probit analysis), $25^{\circ} \mathrm{C}$ as control.

\begin{tabular}{|c|c|c|c|c|c|c|}
\hline Exposure & $\mathrm{Lt}_{50}(\mathrm{~d})$ & $95 \%$ fiducial limits & $\mathrm{Lt}_{95}(\mathrm{~d})$ & $95 \%$ fiducial limits & & \\
\hline Temperature $\left({ }^{\circ} \mathrm{C}\right)$ & & Low & Up & & Low & $\mathrm{Up}$ \\
\hline-25 & 0 & 0 & 0 & 0 & 0 & 0 \\
\hline-20 & 0.1 & 0 & 0.2 & 0.9 & 0.8 & 1.2 \\
\hline-15 & 14.7 & 12.6 & 17.4 & 30.4 & 26.4 & 36.4 \\
\hline-10 & 35.8 & 33.2 & 45.4 & 65.4 & 55.8 & 80.5 \\
\hline-5 & 55.7 & 43.7 & 81.8 & 99.4 & 75.6 & 153.4 \\
\hline 0 & 72.6 & 51.6 & 153.8 & 118.1 & 80.5 & 267.7 \\
\hline 5 & 65.4 & 48.8 & 113.3 & 110.6 & 79.4 & 202.8 \\
\hline Control & 69.0 & 55.3 & 142.8 & 117.7 & 82.7 & 229.2 \\
\hline
\end{tabular}

Table II. Comparison of the effects of low acclimation temperature $\left(5\right.$ and $\left.0{ }^{\circ} \mathrm{C}\right)$ for $1 / 4 \mathrm{~d}, 1 \mathrm{~d}$ and $4 \mathrm{~d}$ on the SCPs of Monochamus alternatus for autumn and overwintering 4-5th instar larvae.

\begin{tabular}{|c|c|c|c|c|c|c|}
\hline 4-5th instar larvae & Treatments & Time & $n$ & Mean $\pm \mathrm{SE}\left({ }^{\circ} \mathrm{C}\right)$ & Range & \\
\hline \multirow[t]{7}{*}{ Autumn } & Non-acclimation & & 20 & $-9.3 \pm 0.4 \mathrm{a}$ & $(-12.5 \sim-4.0)$ & \\
\hline & $5{ }^{\circ} \mathrm{C}$ Acclimation & $1 / 4 \mathrm{~d}$ & 22 & $-11.2 \pm 0.9 \mathrm{ab}$ & $(-18.5 \sim-4.0)$ & $F=9.695$ \\
\hline & & $1 \mathrm{~d}$ & 20 & $-13.1 \pm 1.1 b c$ & $(-20.0 \sim-4.0)$ & d.f. $=3.78$ \\
\hline & & $4 \mathrm{~d}$ & 20 & $-14.1 \pm 0.8 \mathrm{c}$ & $(-19.5 \sim-7.5)$ & $P=0.000$ \\
\hline & $0{ }^{\circ} \mathrm{C}$ Acclimation & $1 / 4 \mathrm{~d}$ & 20 & $-9.6 \pm 1.1 \mathrm{a}$ & $(-20.0 \sim-4.0$ & $F=6.194$ \\
\hline & & $1 \mathrm{~d}$ & 20 & $10.2 \pm 0.9 \mathrm{a}$ & $(-17.5 \sim-5.0)$ & d.f. $=3.76$ \\
\hline & & $4 \mathrm{~d}$ & 20 & $-13.1 \pm 0.9 b$ & $(-22.0 \sim-7.5)$ & $P=0.004$ \\
\hline \multirow[t]{7}{*}{ Overwintering } & Non-Acclimation & & 100 & $-15.7 \pm 0.5 \mathrm{a}$ & $(-22.0 \sim-5.5)$ & \\
\hline & $5{ }^{\circ} \mathrm{C}$ Acclimation & $1 / 4 \mathrm{~d}$ & 20 & $-16.8 \pm 1.1 \mathrm{a}$ & $(-24.0 \sim-8.0)$ & $F=1.729$ \\
\hline & & $1 \mathrm{~d}$ & 100 & $-14.5 \pm 0.4 \mathrm{a}$ & $(-23.0 \sim-6.5)$ & d.f. $=3.236$ \\
\hline & & $4 \mathrm{~d}$ & 20 & $-15.1 \pm 1.0 \mathrm{a}$ & $(-22.0 \sim-6.5)$ & $P=0.162$ \\
\hline & $0{ }^{\circ} \mathrm{C}$ Acclimation & $1 / 4 \mathrm{~d}$ & 20 & $-15.1 \pm 0.8 \mathrm{a}$ & $(-20.0 \sim-8.0)$ & $F=3.656$ \\
\hline & & $1 \mathrm{~d}$ & 100 & $-14.3 \pm 0.4 \mathrm{ab}$ & $(-21.5 \sim-5.0)$ & d.f. $=3.236$ \\
\hline & & $4 \mathrm{~d}$ & 20 & $-12.1 \pm 1.1 b$ & $(-20.0 \sim-5.0)$ & $P=0.013$ \\
\hline
\end{tabular}

Means followed by the different letters are significantly different between treatments (Duncan's multiple range test at $\alpha=0.05$ ).

\subsection{Acclimation efficiency}

A different effect of acclimation was observed on cold hardiness in the autumn larvae compared to the overwintering larvae. Mean SCPs of autumn larvae visibly declined after acclimation (Tab. II). Conversely, after acclimation for $4 \mathrm{~d}$, mortality decrease respectively from $47.5 \%$ to $11.2 \%$ and $9.1 \%\left(5{ }^{\circ} \mathrm{C}\right.$ acclimation: $\mathrm{F}=18.359$, d.f. $=3,12$, $* * * P<0.001 ; 0{ }^{\circ} \mathrm{C}$ acclimation: $\mathrm{F}=14.380$, d.f. $=3,12$, $* * * P<0.001$ ) (Fig. 4). However, the mean SCPs of overwintering larvae did not change (Tab. II) and mortality did not decrease compared to non-acclimated larvae $\left(5{ }^{\circ} \mathrm{C}\right.$ acclimation: $\mathrm{F}=1.141$, d.f. $=3,12, P=0.372 ; 0{ }^{\circ} \mathrm{C}$ acclimation: $\mathrm{F}=0.392$, d.f $=3,12, P=0.761)($ Fig. 5).

\section{DISCUSSION}

In our study, no individuals of $M$. alternatus in any developmental stages survived temperatures below the SCPs, although their SCPs varied from -24.0 to $-5.5{ }^{\circ} \mathrm{C}$ depending on the developmental stages. Therefore, the beetle M. alternatus can be considered to be a freeze-susceptible or freezeavoiding insect [3]. The beetle overwinters as the 4th or 5th instar larvae in the xylem of host boles, but can be found in all the developmental stages during the summer. The mean SCP was found to be lowest in the overwintering 5th instar larvae. The adaptation of the beetle to low temperatures was consistent with its seasonal life history, and the overwintering larvae had significantly stronger cold tolerance compared 


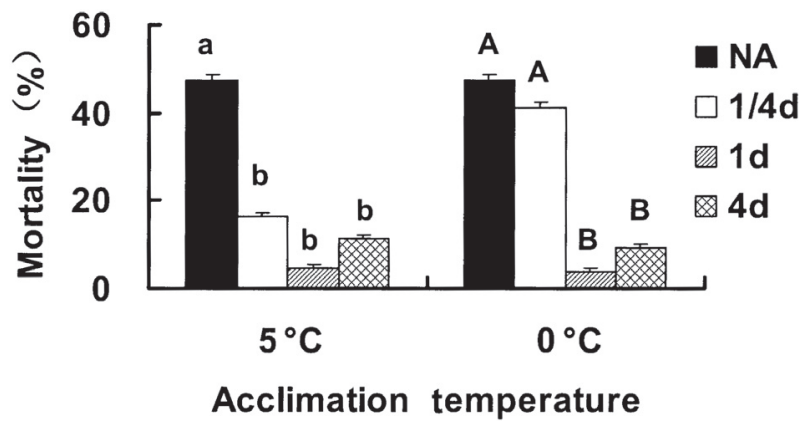

Figure 4. The effects of acclimation to low temperature $\left(5\right.$ or $0{ }^{\circ} \mathrm{C}$ for $1 / 4 \mathrm{~d}, 1 \mathrm{~d}$ and $4 \mathrm{~d}$ ) on mortality (mean \pm S.E.) of Monochamus alternatus $4-5$ th instar autumn larvae. NA represents non-acclimation treatment. Acclimated larvae were exposed to $-10{ }^{\circ} \mathrm{C}$ for $1 / 4 \mathrm{~d}$ to exam their mortality. The columns followed by different letters are significantly different (Duncan's multiple range test at $\alpha=0.05$ ). The bar line is S.E.

to other developmental stages (Figs. 1 and 3). The sequence of mean SCPs among different developmental stages of the beetle had a similar pattern to other beetle species such as Palaearctic cetoniidae, Hypera punctata (Curculionidae) [24,27], ranking the highest in adults and the lowest in the overwintering larvae.

The SCP has proved to be a reliable index to estimate the cold hardiness of the beetle $M$. alternatus. The mean SCP of the overwintering larvae was $-15.7 \pm 0.5{ }^{\circ} \mathrm{C}$ with a minimum value of $-24.0^{\circ} \mathrm{C}$. Acclimation to low temperature did not lower the mean $\mathrm{SCP}$ of the overwintering larvae, although $2 \%$ of the individuals showed SCP value of $-24{ }^{\circ} \mathrm{C}$ after acclimation (Tab. II). Moreover, $-15^{\circ} \mathrm{C}$ was apparently a lethal temperature for the overwintering larvae under which survival declined remarkably with prolongation of the exposure.

We found a significant acclimation effect on the autumn larvae, suggesting that the cold hardiness of those larvae could be increased by acclimation. Conversely, acclimation to low temperature did not enhance cold hardiness of the overwintering larvae. These results suggest that a gradual decline of temperatures in late autumn and early winter could induce natural acclimation, but this effect did not necessarily extend to the overwintering larvae. At the same time, the $\mathrm{LT}_{95}$ of the overwintering larvae was only $30.4 \mathrm{~d}$ at $-15^{\circ} \mathrm{C}$, but more than two months at $-10{ }^{\circ} \mathrm{C}$, and approximately three months at $-5{ }^{\circ} \mathrm{C}$ (Tab. I). Moreover, we found no significant differences in larvae mortalities between exposure to $-5^{\circ} \mathrm{C}$ and 0,5 , and $25^{\circ} \mathrm{C}$. These results indicate that cold injury to the overwintering larvae evidently occurred between -15 and $-10{ }^{\circ} \mathrm{C}$, but temperatures above $-5^{\circ} \mathrm{C}$ were high enough to avoid the cold injury to the overwintering larvae during the winter (Tab. I). Thus, low temperatures in winter should be a limiting factor to the distribution and potential dispersal areas of the beetle. This is similar to swallowtail butterfly, Papilio canadensis and $P$. glaucus in Canada [12].

The ability to survive at low temperature is a critical factor determining the geographical range of the beetle. Meteorological data showed that local minimum temperature generally decreased with increasing latitude in eastern China (Climatic

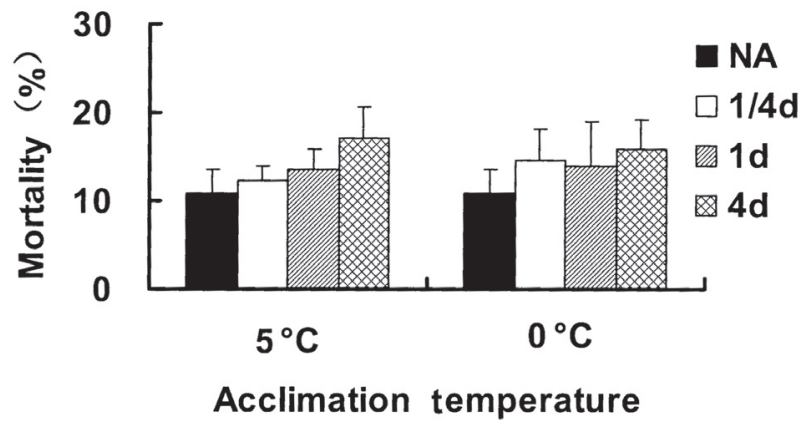

Figure 5. The effects of acclimation to low temperature $\left(5\right.$ or $0{ }^{\circ} \mathrm{C}$ for $1 / 4 \mathrm{~d}, 1 \mathrm{~d}$ and $4 \mathrm{~d}$ ) on mortality (mean \pm S.E.) of Monochamus alternatus 4-5th instar overwintering larvae. NA represents non-acclimation treatment. Acclimated larvae were exposed to $-15{ }^{\circ} \mathrm{C}$ for $1 / 4 \mathrm{~d}$ to exam their mortality. The columns followed by different letters are significantly different (Duncan's multiple range test at $\alpha=0.05$ ). The bar line is S.E.

Atlas of the People's Republic of China, 2002). Therefore, the northern limit of the beetle distribution can be determined by ecological and physiological indexes of cold hardiness combining the SCP with $\mathrm{LT}_{95}$. While the northern limit of the beetle distribution was reported at $40{ }^{\circ} \mathrm{N}$ in Japan $[11,21,25]$, isotherms in China are not always parallel to the latitudinal line due to the diverse topography across the country. Therefore, the geographical limit of species distribution is not always consistent with latitude [23]. The January temperature, which is the lowest in a year in China, is critical for the successful winter survival of the species. Accordingly, the January isotherm rather than latitude is more useful for predicting the northern limit of the beetle distribution. Also, the $\mathrm{LT}_{90}$ is more indicative of the level of cold exposure that may represent a severe threat to the overwintering success at the population level [15], whilst the $\mathrm{LT}_{95}$ should be more reliable for determining the insect survival at individual levels.

We measured the microhabitat temperatures of external and internal tree boles using two Hobo Temperature Recorders 3.6 (Onset Computer Corporation). Our observations indicated that the external temperatures were more variable and with greater fluctuations than the internal temperatures (Fig. 6), but the January mean internal temperature was only $0.04^{\circ} \mathrm{C}$ higher than the corresponding external temperature. Therefore, tree boles could protect the beetle to avoid injury caused by abrupt or extreme low temperatures. The isotherm of January mean air temperature is clearly a critical factor in determining the northern limit of the insect distribution.

In our study, we observed that the lowest SCP for the overwintering larvae was $-24{ }^{\circ} \mathrm{C}$, and that the $\mathrm{LT}_{95}$ for the overwintering larvae was about two months at $-10^{\circ} \mathrm{C}$. Therefore, the extreme minimum temperature above $-24{ }^{\circ} \mathrm{C}$ and mean temperature above $-10{ }^{\circ} \mathrm{C}$ are necessary conditions for $M$. alternatus to establish a population. Since the extreme minimum air temperature was lower than internal temperature of tree trunk, and the $-10{ }^{\circ} \mathrm{C}$ isotherm of January mean air temperature coincides with the $-24{ }^{\circ} \mathrm{C}$ mean annual absolute minimum temperature in China, the $-10{ }^{\circ} \mathrm{C}$ isotherm of January 


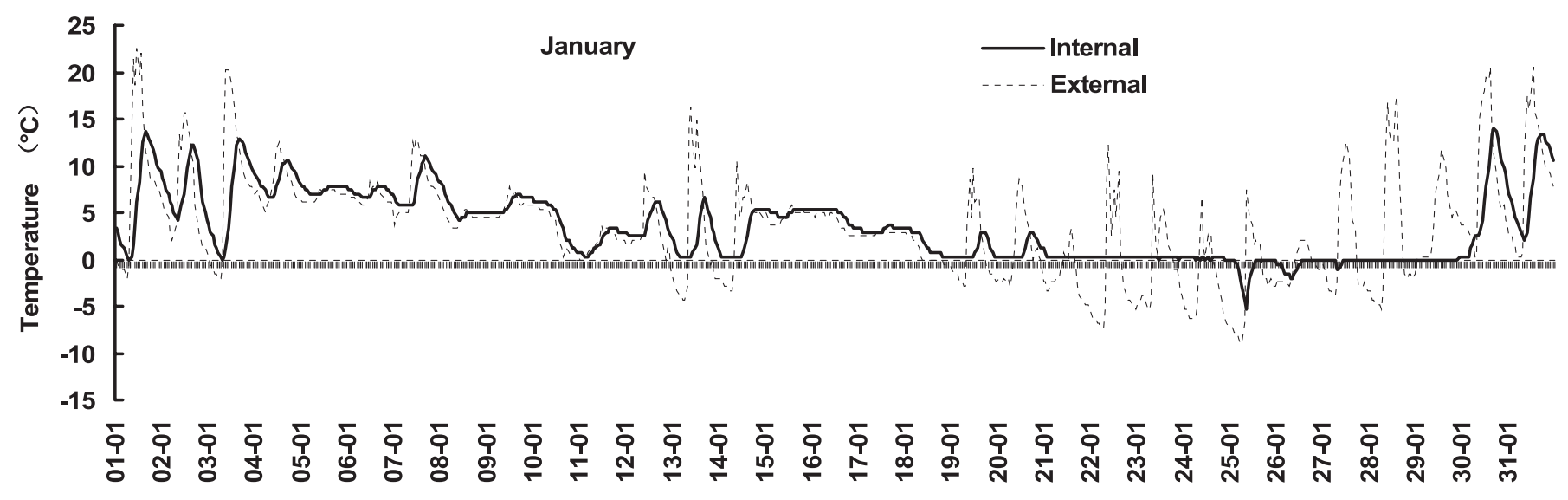

Figure 6. External and internal temperatures of tree boles recorded in Jingting Mountain, Anhui province from 1st-31st January 2004.

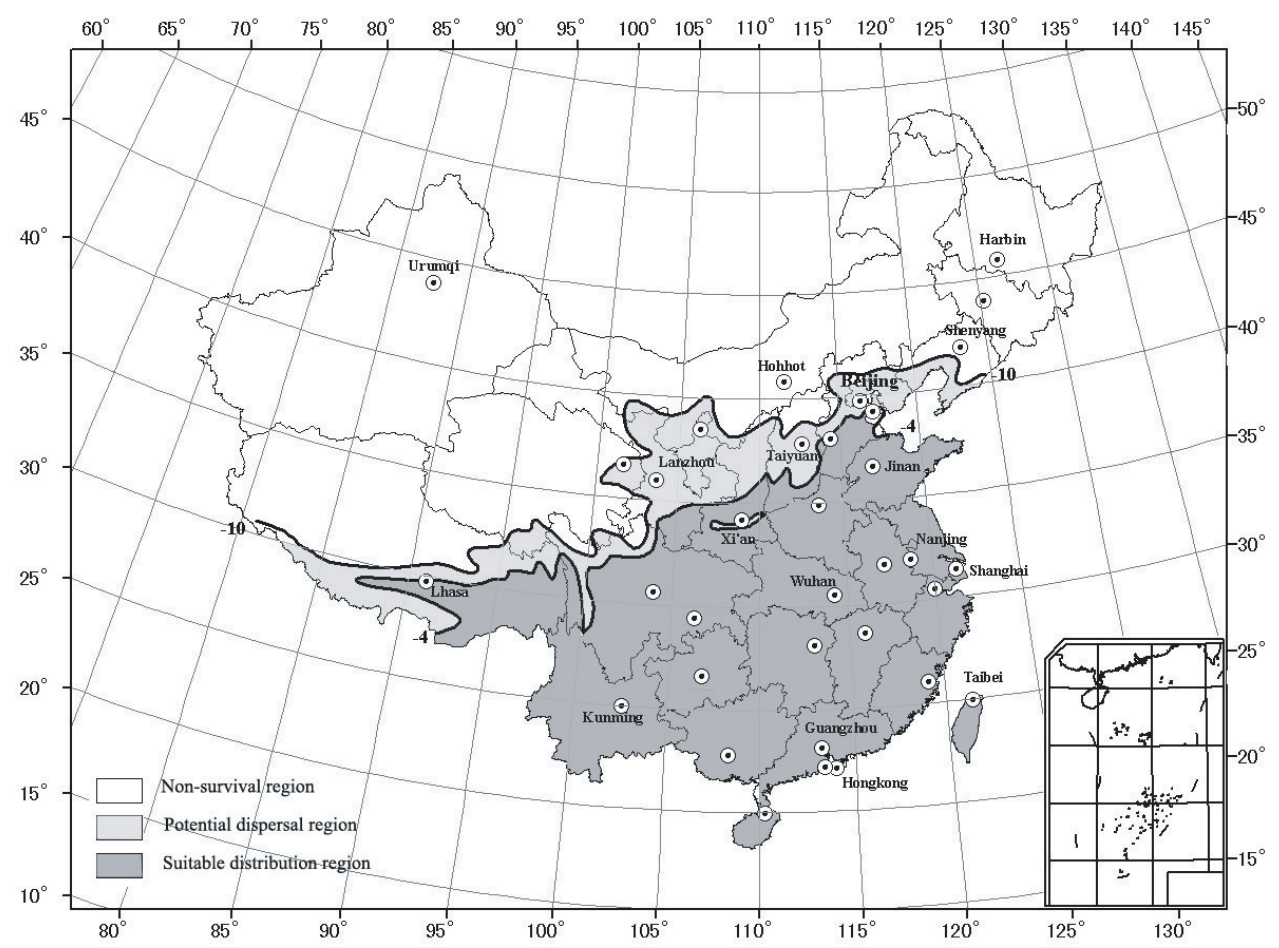

Figure 7. The potential distribution and dispersal areas of Monochamus alternatus in China. Based on -10 and $-4{ }^{\circ} \mathrm{C}$ isotherms of January mean air temperature (Climatological Atlas of the People's Republic of China, 2002 from 1961 1990 meteorological data).

mean air temperature can be considered as the northern limit of M. alternatus distribution in China. In a similar study in the United States, the northern limit of $D$. frontalis distribution was successfully predicted using cold hardiness and climatic information [23]. The winter low temperature limits Papilio canadensis and P. glaucus distribution at high latitudes [12], and $-2{ }^{\circ} \mathrm{C}$ isotherm of the minimum mean temperature in January was proposed as the distribution limit for overwintering of Liriomyza sativae [4].

In China, the $-12 \sim-16{ }^{\circ} \mathrm{C}$ isotherm of mean annual absolute minimum temperature coincides with the $-4{ }^{\circ} \mathrm{C}$ isotherm of January mean air temperature. We herein propose that the geographic distribution and potential dispersal region of $M$. al- ternatus should be determined by the -10 and $-4{ }^{\circ} \mathrm{C}$ isotherms divided into 3 regions (Fig. 7): (1) the non-survival region below the $-10{ }^{\circ} \mathrm{C}$ isotherm of January mean air temperature; (2) potential dispersal region between the -10 and $-4{ }^{\circ} \mathrm{C}$ isotherms; and (3) the suitable survival regions above the $-4{ }^{\circ} \mathrm{C}$ isotherm. In the non-survival region, the beetle should not survive because of cold-induced death. In the potential dispersal region, the low temperature usually results in high mortality, as cold injury to the overwintering larvae evidently occurs between -15 and $-10{ }^{\circ} \mathrm{C}$. However, an increase in temperature due to global warming would make this region more favourable for beetle establishment. In the suitable distribution region, $M$. alternatus could safely overwinter and break-out 
frequently. Although Lhasa in Tibet and Kunming in Yunnan province lie within this region, these two locations should not be considered suitable areas, because their mean air temperatures in July are only 15.1 and $19.8{ }^{\circ} \mathrm{C}$, which are lower than the $21.3{ }^{\circ} \mathrm{C}$ oviposition threshold [11]. This predicted distribution, based on cold tolerance parameters matched well with the current population dynamics and distribution records of the beetle in southern and central parts of China [25, 26, 29]. The Monochamus vectors of PWN are distributed throughout most of the continents with overlapping distribution in Europe, North American and China [18,29]. Some species of Monochamus seem adaptable to colder regions, i.e. M. sutor and $M$. saltuarirs in northeastern China, M. galloprovinialis in the whole of Europe except for Scandinavia and Siberia, and M. scutellatus scutellatus in Alaska and Canada $[6,18,28]$. These Monochamus species could have stronger cold hardiness than $M$. alternatus, but their cryobiology and transmitting ability as the vectors of the wilt disease needs to be examined further.

The $20{ }^{\circ} \mathrm{C}$ July mean air temperature isotherm has been considered as the limit for occurrence of pine wilt disease in North America and Europe by using the methods of the Pest Risk Analysis (PRA) based on the occurrence in Japan [18]. However, in China, the $20{ }^{\circ} \mathrm{C}$ July mean air temperature isotherm may reach the northernmost Heilongjiang province, where susceptible pines and other vectors such as $M$. sutor and $M$. saltuarirs are present, but both $M$. alternatus and pine wilt disease do not occur [29]. Based on the field survey, the distribution range of the beetle in China is more restricted than that of its relative host trees, but larger than the distribution of the pine wilt disease. Although the range of wilt disease is gradually expanding year after year [16,29], it is limited within the distribution areas of the beetle. Because of its short history in China and other vectors in the field, in theory the disease is likely to extend farther and even exceed the distribution range of the beetle. The beetle is one of the most important vectors of the disease in China, control of the beetle itself is a main approach to depress the wilt disease. Therefore, it is very useful to determine the potential distribution range of the beetle, to control the beetle as pest itself and also the wilt disease. If the range of the disease outbreak goes beyond the beetle's range in northern regions, there are likely to be other vector species to transmit the disease. Therefore, the $-10{ }^{\circ} \mathrm{C}$ January mean air temperature isotherm as northern limit of $M$. alternatus could provide useful information for prediction and management of both M. alternatus and B. xylophilus in China.

Acknowledgements: We sincerely thank Drs. Xiao-hong Jing, Bing Chen, Ying-xin Gao and Wen-xia Dong for help with the research. We are especially grateful to Dr. David L. Kulhavy and two anonymous reviewers for their valuable comments on improving the manuscript. This work was supported by grants from the Chinese Academy of Sciences (No. KZSCX1-SW-13-0202) and State Key Laboratory of Integrated Management of Pest Insects and Rodents (No. 200404).

\section{REFERENCES}

[1] Ayres M.P., Scriber J.M., Local adaptation to regional climates in Papilio canadensis (Lepidoptera: Papilionidae), Ecol. Monogr. 64 (1994) 465-482.

[2] Bale J.S., Cold hardiness and overwintering of insects, Agric. Zool. Rev. 3 (1989) 157-192.

[3] Bale J.S., Classes of insect hardiness, Funct. Ecol. 7 (1993) 751753.

[4] Chen B., Kang L., Implication of pupal cold tolerance for the northern over-wintering range limit of the leafminer Liriomyza sativae (Diptera: Agromyzidae) in China, Appl. Entomol. Zool. 40 (2005) 437-446.

[5] Cheng H., Lin M., Li W., Fang Z., The occurrence of a pine wilting disease caused by a nematode found in Nanjng, For. Pest Dis. 4 (1983) 1-5.

[6] Evans H.F., McNamara D.G., Braasch H., Chadoeuf J., Magnusson C., Pest Risk Analysis (PRA) for the territories of the European Union (as PRA area) on Bursaphelenchus xylophilus and its vectors in the genus Monochamus, Bull. EPPO. 26 (1996) 199-249.

[7] Hodkinson I.D., Bird J., Miles J.E., Bale J.S., Lennon J.J., Climatic signals in the life histories of insects: the distribution and abundance of heather psyllids (Strophingia spp.) in the UK, Funct. Ecol. 13 (1999) 83-95

[8] Jing X.H., Kang L., Geographical variation in egg cold hardiness: a study on the adaptation strategies of the migratory locust Locusta migratoria L., Ecol. Entomol. 28 (2003) 151-158.

[9] Jing X.H., Kang L., Overview and evaluation of research methodology for insect cold hardness, Entomol. Knowledge. 41 (2004) 7-10.

[10] Kimura M.T., Cold and heat tolerance of drosophilid flies with reference to their latitudinal distributions, Oecologia 140 (2004) 442449.

[11] Kobayashi F., Yamane A., Ikeda T., The Japanese pine sawyer beetle as the vector of pine wilt disease, Annu. Rev. Entomol. 29 (1984) $115-135$.

[12] Kukal O., Ayres M.P., Scriber J.M., Cold tolerance of the pupae in relation to the distribution of swallowtail butterflies, Can. J. Zool. 69 (1991) 3028-3037.

[13] Linit M.J., Nematode-vector relationships in the pine wilt disease system, J. Nematol. 20 (1988) 227-235.

[14] Maehara N., Futai K., Factors affecting both the numbers of the pinewood nematode, Bursaphelenchus xylophilus (Nematoda: Aphelenchoididae), carried by the Japanese pine sawyer, Monochamus alternatus (Coleoptera: Cerambycidae), and the nematode's life history, Appl. Entomol. Zool. 31 (1996) 443-452.

[15] Mcdonald J., Head J., Bale J.S., Walters K.A., Cold tolerance, overwintering and establishment potential of Thrips palmi, Physiol. Entomol. 25 (2000) 159-166.

[16] Ning T., Fang Y.L., Tang J., Sun J.H., Advances in research on Bursaphelenchus xylophilus and its key vector Monochamus spp. Entomol. Knowledge. 41 (2004) 97-104.

[17] Roland J., Mackey B.G., Cooke B., Effects of climate and forest structure on duration of forest tent caterpillar outbreaks across central Ontario, Canada, Can. Entomol. 130 (1998) 703-714.

[18] Rutherford T.A., Mamiya Y., Webster J.M., Distribution of pine wilt disease with respect to temperature in North American, Japan, and Europe, Can. J. For. Res. 17 (1987) 1050-1059.

[19] Rutherford T.A., Mamiya Y., Webster J.M., Nematode-induced pine wilt disease: factors influencing its occurrence and distribution, For Sci. 36 (1990) 145-155.

[20] Shintani Y., Ishikawa Y., Geographic variation in cold hardiness of eggs and neonate larvae of the yellow-spotted longicorn beetle Psacothea hilaris, Physiol. Entomol. 24 (1999) 158-164. 
[21] Song Y.S., Zang X.Q., Analysis of adaptation and quarantine countermeasure to Bursaphelenchus xylophilus in China, For. Pest Dis. 4 (1989) 38-41.

[22] Swaine J.M., The factors determining the distribution of NorthAmerican bark beetles, Can. Entomol. 58 (1925) 261-267.

[23] Ungerer M.J., Ayres M.P., Lombardero M.J., Climate and the northern distribution limits of Dendroctonus frontalis Zimmermann (Coleoptera: Scolytidae), J. Biogeogr. 26 (1999) 1133-1145.

[24] Vernon P., Vannier G., Freezing susceptibility and freezing tolerance in Palaearctic cetoniidae (Coleoptera), Can. J. Zool. 79 (2001) $67-74$.

[25] Wang Q., Study on biogeography of Monochamus spp., Scientia Silvae Sinicae, 24 (1988) 297-304.
[26] Wang S.F., Monochamus alternatus, in: Xiao G.R. (Ed.), Forest insects of China, Chinese Forestry Press, Beijing, China, 1992, pp. 483-485.

[27] Watanabe M., Tanaka K., Overwintering status and cold hardness of Hypera punctata (Coleoptera: Curculionidae), Cryobiology 35 (1997) 270-276.

[28] Wingfield M.J., Blancehette R.A., Nicholis T.H., Robbins K., The pine wood nematode: a comparison of situation in the United States and Japan, Can. J. For. Res. 12 (1982) 71-75.

[29] Yang B.J., Pan H.Y., Tang J., Wang Y.Y., Wang L.F., Chapter I. Distribution history and damage of pine wilt nematode, in: Yang B.J., Pan H.Y., Tang J., Wang Y.Y., Wang L.F. (Eds.), Bursaphelenchus xylophilus, Chinese Forestry Press, Beijing, 2003, pp. 1-9. 